\title{
Technology and Government Effort, A Two-headed Animal within the Competitiveness Index of the Travel and Tourism Industry
}

\author{
Jean-Luc Pradel Mathurin Augustin ${ }^{1}$, Shu-Yi Liaw ${ }^{2}$ \\ ${ }^{1}$ Department of Tropical Agriculture and International Cooperation, National Pingtung University of Science and \\ Technology, Pingtung City, Taiwan \\ ${ }^{2}$ Management College, Computer Centre, National Pingtung University of Science and Technology, Pingtung \\ City, Taiwan \\ Correspondence: Shu Yi-Liaw, Management College, Computer Centre, National Pingtung University of Science \\ and Technology, 1 Hsueh-Fu Road, Neipu Township, Pingtung, Taiwan.
}

Received: July 30, 2018

Accepted: August 28, 2018

Online Published: August 30, 2018

doi:10.5539/ibr.v11n9p144

URL: https://doi.org/10.5539/ibr.v11n9p144

\begin{abstract}
Technology and social indicators as most important to tourism, give a two-headed feel to the index created to measure the industry's competitiveness. To prove their importance and multi-dimensional relationship, this study uses multivariate analysis techniques to investigate the relationship between them while focusing on three regions. The results indicate $78.1 \%$ of shared variance between the constructs alongside significant $R^{2}$ effect and canonical correlation score, proving their relationship and importance. Five clusters were identified with the lower two needing improvements in both factors to positively influence tourism competitiveness. The top-performers displayed desirable scores while the middle class needed technology improvements.
\end{abstract}

Keywords: Canonical correlation analysis, ICT readiness, prioritization of travel and tourism, government effort, TTCI

\section{Introduction}

The travel and tourism industry continues to grow, being the difference-maker for millions of people by the number of business opportunities and jobs it creates. As reported by the World Economic Forum (WEF), in 2016, the industry contributed up to $10.2 \%$ of global GDP, generating 292 million jobs in the process (Crotti \& Misrahi, 2017). This reveals the importance of the sector, and is the reason many researchers have been and are continuously interested in measuring its competitiveness (Kozak and Rimmington, 1998, 1999; Haahti and Yavas, 1983; Dwyer et al., 1999, 2000; Gooroochurn \& Sugiyarto, 2005). Augustin \& Liaw (2017) reported previous studies attempting to measure competitiveness were based either on a demand or a supply point of view, the two specific methods in the literature (Dwyer, Mistilis, Forsyth, \& Rao, 2000a, 2000b; Garau, 2006; Kozak \& Rimmington, 1999; Papatheodorou, 2002).

Many researchers proposed a number of indicators susceptible to measure competitiveness (Gooroochurn \& Sugiyarto, 2005; Crotti \& Misrahi, 2015, 2017; Augustin \& Liaw, 2017). However, the eight main indicators proposed in the Competitiveness Monitor of Gooroochurn and Sugiyarto (2005) had the ability to encompass the broad definition of tourism competitiveness. The ability to draw comparisons across countries and over time is one of the many advantages of the technique, and the indicators are: price, openness, technology, human tourism, social development, infrastructure, human resources and environment. As they computed the aggregated index, they later found that social and technology indicators could be considered the most important considering they had a higher weight than any other indicator. As widely as it is used, this index received several criticisms from various researchers around the globe mainly for the arbitrary weight attributed to variables (Pulido-Fernández \& Rodríguez-Diaz, 2016).

Number of authors in the literature pointed out the importance of technology and the convenience it brings to travelers and tourists or simply to tourism competitiveness (Lee et al., 1996; Crouch \& Ritchie, 1999; Kozak \& Rimmington, 1999; Dwyer \& Kim, 2003; Garau, 2006; Pulido-Fernandez \& Rodriguez-Diaz, 2016; Augustin \& Liaw, 2017). Thus, one might be tempted to see technology as the most important factor to tourism competitiveness. Other authors such as Perles (2004) pointed out various social indicators as determining factors 
of competitiveness, although difficult to characterize. These can be seen as the two heads of an animal, but such considerations are supplementary arguments proving that both constructs are of high importance to the competitiveness index itself. Not because an animal has two heads does it go in two different directions; the heads would have to work as one unit and lead the body in one direction.

Despite the identified separate importance of technology and government effort in tourism competitiveness and despite the number of studies focusing on travel and tourism competitiveness, the association between the two has not been clearly investigated. However, the acceptance in the literature that both constructs are of great importance raises questions as to what kind of relationship exists between the two constructs.

It is true that researchers would normally expect these constructs to be correlated, however the present study addresses this gap by exploring and providing statistical and scientific evidence of the relationship between technology (represented by ICT Readiness within the TTCI), and government efforts to help the tourism industry whether it be by promotion efforts, creating their brand or by making specific decisions facilitating the development and competitiveness of the industry (represented by Prioritization of Travel and Tourism in the TTCI). Taking into account the multi-faceted nature of both constructs as defined within the TTCI is key to the outcomes of the present study, and this has directed towards canonical correlation analysis (CCA) which will be used to yield the results. The research question of interest is whether the set of technology variables and the set of government effort variables are related to each other and in which ways. If it is found that the two are related, the magnitude of the existing relationship will be investigated in order to deduct how the variables impact each other. This will help draw useful recommendations related to the groups of countries pertaining to the sample under study so as to figure out how to approach the relationship of the two constructs within their own economy taking into account the nature of the existing relationship.

The present study aims at exploring and understanding how technology and government effort, two constructs important to travel and tourism competitiveness, relate to each other using the Canonical Correlation Analysis method. In the literature, previous studies have explored the separate importance of each concept; this study will allow to mirror their importance to tourism competitiveness taken as correlated pieces of a whole framework translated into the competitiveness index. Therefore, this paper will take into account the multi-faceted nature of each construct in the process of exploring their relationship. Although not a primary objective of this paper, a classification of the countries pertaining to the sample under study will be made through the results of a cluster analysis based on the two constructs, allowing for more in depth suggestions. The specific objectives of this research are to:

i. determine whether the sets of variables of the technology and social indicator are related to each other

ii. explore the magnitude of the relationship that may exist between the sets of variables of the two indicators

iii. explain the nature of the relationship that exists between the sets of variables by measuring the relative contribution of each variable to the canonical functions that are extracted.

The present study would therefore suggest how crucial and vital it is for tourist destinations to pay a close attention to the existing relationship between the two constructs considering it might yield numerous benefits to the industry or their national economy. Managers and decision makers could draw conclusion from their country positioning in the cluster analysis and think of ways to improve their tourism industry.

\section{The Tourist Destination, a Competitiveness Approach}

In recent years, the rapid development of tourism due to numerous factors such as technology development and its integration into development plans of several national economies has drawn the attention of researchers around the globe. Let alone defining the tourist destination from a competitiveness standpoint was necessary to better understand how tourism impacts other industries, but it was first and foremost important to define and understand how can a country or territory be considered competitive as one talks about tourism. As countries are eager to increase their market share of travel and tourism, the concept "tourism competitiveness" arises and gains importance for governments and policy makers.

Buhalis (2000) considered destination as a number of tourism products, services and experiences designed to provide consumers with an integrated experience (Khin et al., 2014). He further mentioned that the amalgam of tourism products and services offered to tourists are consumed under the brand name of the destination. Tanja et al. (2011) followed the definition of Ritchie \& Crouch (2003) where destination competitiveness is seen as the ability of a country to create additional values and, therefore, increase national wealth by managing assets and processes, attractiveness, aggressiveness and proximity and by integrating these relationships within an 
economic and social model that takes into account a destination's natural capital and its preservation for future generations. The OECD recently proposed its own definition of tourism competitiveness for a destination and it is seen as the ability of the place to optimise its attractiveness for residents and non-residents, to deliver quality innovative and attractive tourism services to consumers and to gain market shares on the domestic and global market places, while ensuring that the available resources supporting tourism are used efficiently and in a sustainable way (Dupeyras \& MacCallum, 2013).

Competitiveness is a concept that is considered complex, and supplying an exact and accurate definition for it has always been problematic, let alone measuring it. It goes the same about tourism competitiveness. Measuring tourism competitiveness has been a concern for countless researchers and this explains why there are various proposed models in the literature aiming at its measurement. Gooroochurn and Sugiyarto (2005) reported that the identification of the elements of competitiveness is contentious given the conceptual problems embodied in its definition as it is a relative and multidimentional concept (Scott \& Lodge, 1985).

There is a large number of studies focusing on approaches to measure competitiveness in tourism (Crouch \& Ritchie, 1999, 2003; Dwyer et al., 2000a, 2000b; Dwyer \& Kim, 2003; Haahti \& Yavas, 1983; Kozak \& Rimmington, 1998, 1999). But, some researchers believed that there is not one approach to measuring destination competitiveness suitable to all countries and no single set of indicators could be applied to all destinations at all times (Eright \& Newton, 2004, 2005; Gomezelj \& Mihalic, 2008; Khin et al., 2014).

\subsection{The Travel and Tourism Competitiveness Index (TTCI)}

TTCI is the main focus of the Travel and Tourism Competitiveness Report (TTCR) which covers a large number of countries in each edition. This report, produced on a 2-year basis, analyses the performances of numerous economies through the TTCI by revealing important insights about strengths and weaknesses (areas that would require special attention for development) of each analyzed country in order to enhance the competitiveness of the sector. The index unveils the areas where improvements are needed through the analysis and comparison of countries performances, providing solid grounds for policy and business decisions (Augustin \& Liaw, 2017; Crotti \& Misrahi, 2017).

The index originated from an innovative methodology that was presented for measuring and monitor tourism competitiveness using a wide range of relevant individual indicators grouped into eight main indicators able to encompass the broad definition of tourism competitiveness: price, openness, technology, infrastructure, human, tourism, social development, environment and human resources (Gooroochurn \& Sugiyarto, 2005). This methodology was later replicated and adapted by the WEF in 2007 with the production of the TTCR.

The 2015 and 2017 version of the TTCR featured the new TTCI's framework which is a construct of 4 sub-indexes, 14 pillars and 90 individual indicators, all distributed among the pillars (Augustin \& Liaw, 2017; Crotti \& Misrahi, 2015, 2017). The subindexes and pillars are arranged in the following order: Enabling Environment (business environment, safety and security, health and hygiene, human resources and labor market, ICT readiness), Travel and Tourism Policy and Enabling Conditions (prioritization of travel and tourism, international openness, price competitiveness, environmental sustainability), Infrastructure (air transport infrastructure, ground and port infrastructure, tourist service infrastructure) and Natural and Cultural Resources (natural resources, cultural resources and business travel) (Crotti \& Misrahi, 2015, 2017). The present study is directed towards two specific pillars, namely ICT readiness and prioritization of travel and tourism. Technology and social indicators were the two most important factors in Gooroochurn and Sugiyarto's competitiveness monitor considering they presented the highest weights (2005). The weighting procedure is also one of the main criticism of the index because it is deemed arbitrary (Augustin \& Liaw, 2017).

\subsection{The ICT Readiness Indicator}

The role technology has played in the travel and tourism industry is extensively discussed in the literature. One of the main changes the development of information and communication technologies brought by is the radical shift in consumer behavior. Consumers had very little access to information in the past, and travel planning for example was not as easy as it is nowadays. In today's day and age, the consumer has access to an important amount of information with just a few clicks on a browser (Chung \& Koo, 2015). The internet's appearance is therefore among the major technology developments that brought significant changes in the structure of the tourism industry considering the amount of information available online consumers can access at any given time (Aramendia-Muneta \& Ollo-Lopez, 2013). Buhalis \& Law (2008) reported that the real effects of ICTs that we are experiencing since the year 2000 are the results of the emphasis on technology witnessed over the previous two decades, making room for the emergence of new businesses, services and tools thus making it easier for all stakeholders worldwide to interact. Many researchers believe that ICTs play a pivotal and major role in tourism 
competitiveness (Aramendia-Muneta \& Ollo-Lopez, 2013; Bojnec \& Kribel, 2004; Buhalis \& Kaldis, 2008; Buhalis \& O'Connor, 2005), but it is hardly an unanimous perception given some doubted that ICTs really impact tourism competitiveness (Mihalic, 2007) or even doubted the existence of a relationship between the adoption of ICTs and tourism competitiveness' improvements (Dos Santos et al., 1993).

With the apparition of the internet came the extensive use of social media platforms. Is considered social media all internet-based applications carrying consumer-generated content created by consumers from their own relevant experience and shared or stored online for easy access by other consumers (Chung \& Koo, 2015; Xiang \& Gretzel, 2010). Social media provides a platform where consumers can interact and search for services, share ideas, thoughts, experiences, perspectives, information (Chan \& Guillet, 2011; Chung \& Koo, 2015; Sigala et al., 2012). Before the use of social media, tourists had limited access to information through travel magazines, newspapers and books which have been replaced in recent years by internet websites, blogs or simply posts and/or comments from other consumers giving insights or recommendations (Chung \& Koo, 2015).

In the TTCR, the technology indicator, ICT Readiness, is a pillar of eight indictors: ICT use for biz-to-biz transactions [ICT1], ICT use for biz-to-consumer transactions [ICT2], internet users (\% pop.) [ICT3], fixed-broadband internet subscriptions [ICT4] mobile-cellular telephone subscriptions (/100 pop.) [ICT5], mobile broadband subscriptions (/100 pop.) [ICT6], mobile network coverage (\% pop.) [ICT7] and quality of electricity supply [ICT8] (Crotti \& Misrahi, 2015, 2017).

\subsection{The Social Indicator}

Prioritization of Travel and Tourism draws the attention on the role of government in tourism and the implication of government in tourism planning and development is a topic that has drawn interest of the scientific community for as long as one can remember considering that it is well documented in the literature that local governments are the most important authorities in establishing tourism development policies (Bouquet \& Winter, 1987; Madrigal, 1995; Pearce, 1989). However, Bramwell (2011) insisted on the importance of a broad social theory such as "political economy" to better understand governments' role in tourism development. Governments are considered the key players in tourism development and planning (Wang \& Bramwell, 2012) as much of the responsibility to manage and develop tourism is on local governments (Elliott, 1997; Nunkoo, 2015; Ruhanen, 2013). Considering the proximity to various aspects of tourism and the well-oriented knowledge of communities entitled to local governments, their constant involvement in tourism seems justified (Aronsson, 2000). Tourism policy decisions are of the domain of governments and, as a result, they are more often than not held accountable for such (Bramwell, 2011). The governments are expected to create tourism policies determining the level of benefits and costs of tourism for local communities (Citrin, 1974).

Elliott (1997) reported that the implementation of tourism policy essentially depends on the broader political, economic and social environment. But, we need to understand that policy implementation is the process where policy ideas and plans are translated into practice (Dredge \& Jenkins, 2007). The different perspectives of researchers who studied policy implementation suggested three approaches in identifying the influence of diverse variables in the process: the top-down, the bottom-up and the synthesis approach. The latter originated from identified weaknesses of the first two. As suggested by number of researchers through the guidance of the synthesis approach, four factors are identified: the macro-environment, the institutional arrangements, inter-organizational relations \& co-ordination and the interest groups. Wang \& Ap (2013) highlighted that the macro-environment (which is the economic and social environment) influences the roles that government would take in tourism development.

The social indicator represented by the pillar Prioritization of Travel and Tourism in the TTCI has the following individual indicators: government prioritization of travel and tourism industry [P1], travel and tourism government expenditure (\% government budget) [P2], effectiveness of marketing and branding to attract tourists [P3], comprehensiveness of annual travel and tourism data (0-120 best) [P4], timeliness of providing monthly/quarterly travel and tourism data (0-21 best) [P5] and country brand strategy rating (1-10 best) [P6].

\section{Data and Methodology}

This section includes the data source and introduces the methods that were used in the present study.

\subsection{Data}

The data used here are taken from the TTCR featuring the TTCI. Two pillars, namely ICT Readiness (technology component with eight individual indicators) and Prioritization of Travel and Tourism (social component with six indicators) are at the core of this study in regards to their importance to travel and tourism. Three regions were chosen: the Asia-Pacific considered as the second largest tourism market and most improved region in terms of 
travel and tourism by the World Economic Forum given their performance in the last two reports (2015 and 2017), the Americas being the second most improved region and Europe \& Eurasia, the region with the largest tourism market and the strongest overall performance.

\subsection{Methods}

At first, simple relationships between the variables are explored using bivariate correlations. This allows to attest whether there is a certain association between the two constructs and how strong is the relationship between them. However, this offers no indication on the causal direction of a relationship, if one exists; which explains the second step where a canonical correlation analysis is performed to explore the strength and nature of the association between technology and government efforts within the index. For the analyses, SPSS 22 and STATISTICA 13 were used to generate the results.

The use of canonical correlation analysis is justified since it provides a statistical analysis where each subject is measured on two sets of variables and there is a focus on knowing how the two sets relate to each other. In canonical correlation, there are several variables on both sides of the equation and the analysis combines the sets of variables to produce, for each side, a predicted value with the highest correlation with the predicted value on the other side. Fox \& Hammond (2017), in a study of psychopathy and impulsivity, reported the combination of variables on each side can be thought of as a dimension that relates the variables on one side to the variables on the other side (Tabachnick \& Fidell, 1996). Edwards \& Bagozzi (2000) studied the nature and direction between constructs and measures; they concluded that for direct formative models such as the one here, canonical correlation analysis is suitable because it uses observed measures to creates weighed linear composites serving as conceptual variables. As technology and government efforts are normally multivariate, an analytic approach allowing for multiple independent variables seemed more suitable for the study, and therefore was adopted. The technique is well explained in Sherry \& Henson's research (2005).

In order to draw useful conclusions, a cluster analysis was then conducted based on the two constructs to provide more oriented and informed recommendations for each group of countries.

\section{Results and Discussion}

This section presents the results of the analyses conducted which includes a simple bivariate correlation study as well as a canonical correlation analysis to identify how the two sets of variables relate to each other within the TTCI, namely technology and government efforts supporting the tourism industry.

\subsection{Bivariate Correlation Results}

The simple relationship between government effort and technology within the TTCI was investigated using Pearson's product-moment coefficient and it proved that, based on the dataset used, there is a moderate significant relationship between them $(r=0.439, \mathrm{p}<0.01)$. Considering these two pillars are part of the framework that ultimately leads to the index, it is useful to investigate at once the strength of a linear association between them and the index, if any. The reliability analysis will be performed as well to make sure of the reliability of the measurements.

Table 1. Correlation between Technology and Government effort

\begin{tabular}{cccc}
\hline Variable & Technology & Government Effort & TTCI \\
\hline Technology & 1 & & \\
Government Effort & $0.439 * *$ & 1 & 1 \\
TTCI & $0.774 * *$ & $0.537 * *$ & \\
\hline$* *$ cort & &
\end{tabular}

\footnotetext{
**correlations significant at $p<0.01$ level $(2$ tailed $)$
}

It is observed in Table 1 that, for the index itself, there is a strong and significant positive linear association with technology whereas there is a moderate significant positive linear association with government efforts. This supports the findings of Augustin \& Liaw (2017) in their consistency analysis of the competitiveness index in the Asia-Pacific region where they concluded that the index is strongly correlated to its technology component whereas it is moderately associated to the government effort component.

Taken independently, each set yielded the reliability results that follow. The set of technology indicators proved to have a high reliability of 0.91 (standardized value) with a strong positive correlation between items while the set of government efforts indicators has a reliability of 0.7 (standardized value) with a moderate positive linear correlation between items. The overall reliability equaled 0.88 on standardized value. These results suggest that the reliability for both sets of items is good enough considering Tavakol and Dennick (2011) mentioned that reliability is expressed as a number between 0 and 1 while Leontitis \& Pagge (2007) stated that there is a good level on consistency when reliability is closer to 1 . 


\subsection{Canonical Correlation Analysis' Results}

A canonical correlation analysis was conducted using the eight technology indicator's variables as predictors of the six government effort's variables to evaluate the multivariate shared relationship between the two variable sets. The analysis yielded only three statistically significant functions amongst the six functions removed with squared canonical correlations of $0.495,0.309$ and 0.185 for each successive significant function. Collectively, the model across all functions was statistically significant using the Wilks's $\lambda=0.220$ criterion, $F(48,373.09)=$ $2.804, \mathrm{p}<0.001$. Because Wilks's $\lambda$ represents the variance unexplained by the model, $1-\lambda$ yields the full model effect size in an $\mathrm{r}^{2}$ metric. Thus, for the set of three canonical functions, the $\mathrm{r}^{2}$ type effect was 0.781 , which indicates that the full model explained a substantial portion, about $78 \%$ of the variance shared between the variable sets.

Table 2. Canonical correlation between government effort and technology

\begin{tabular}{ccccccr}
\hline Function & Eigenvalue & $\%$ & Cum. \% & Canonical R & Sq. Corr & Wilks's lambda \\
\hline 1 & 0.979 & 50.7 & 50.7 & 0.703 & 0.495 & $0.220^{* *}$ \\
2 & 0.447 & 23.2 & 27.9 & 0.556 & 0.309 & $0.435^{* *}$ \\
3 & 0.226 & 11.7 & 85.6 & 0.430 & 0.185 & $0.629 *$ \\
\hline
\end{tabular}

$* * p<0.001$ and $* p<0.05$

The dimension reduction analysis eases the path to test the arrangement of functions for statistical significance. As noted in Table 2, the first three functions were statistically significant $(p<0.001)$ although at a different significance level in the case of the third function $(\mathrm{p}<0.05)$. Given the $\mathrm{R}_{\mathrm{c}}{ }^{2}$ for each statistically significant function, they explained $49.5 \%, 30.9 \%$ and $18.5 \%$ of shared variance respectively. The last three (non statistically significant) functions only explained $14.6 \%, 8.6 \%$ and $1.2 \%$ respectively of the remaining variance after the extraction of prior statistically significant functions (see Dimension Reduction Analysis in Appendix).

Table 3 presents the standardized canonical function coefficients and structure coefficients for the statistically significant functions, as well as the squared structure coefficients and the communalities $\left(\mathrm{h}^{2}\right)$ for each variable. As reported by Fox \& Hammond (2017), it is important that these functions manifest a clear and unambiguous structure because of the residual nature of the variance that they are based upon.

Table 3. Canonical Solution for Functions 1 to 3

\begin{tabular}{|c|c|c|c|c|c|c|c|c|c|c|}
\hline \multirow{2}{*}{$\begin{array}{c}\text { Varia } \\
\text { ble }\end{array}$} & \multicolumn{3}{|c|}{ Function 1} & \multicolumn{3}{|c|}{ Function 2} & \multicolumn{3}{|c|}{ Function 3} & \multirow{2}{*}{$h^{2}(\%)$} \\
\hline & Coef. & $r_{s}$ & $r_{s}^{2}(\%)$ & Coef. & $r_{s}$ & $r_{s}^{2}(\%)$ & Coef. & $r_{s}$ & $r_{s}^{2}(\%)$ & \\
\hline ICT1 & 1.330 & 0.965 & 93.06 & 1.591 & -0.170 & 2.88 & 0.804 & 0.048 & 0.23 & 96.18 \\
\hline ICT2 & -0.459 & $\underline{0.764}$ & 58.39 & -1.896 & -0.542 & 29.43 & -0.115 & 0.085 & 0.72 & $\underline{88.54}$ \\
\hline ICT3 & 0.010 & $\underline{0.631}$ & 39.83 & -0.874 & $-\overline{0.414}$ & 17.14 & -0.309 & -0.063 & 0.40 & $\underline{57.36}$ \\
\hline ICT4 & -0.178 & 0.666 & 44.35 & 0.353 & -0.327 & 10.69 & 1.091 & 0.084 & 0.70 & 55.74 \\
\hline ICT5 & 0.011 & $\overline{0.292}$ & 8.54 & 0.086 & -0.089 & 0.79 & 0.167 & 0.019 & 0.04 & 9.37 \\
\hline ICT6 & -0.020 & $\underline{0.641}$ & 41.11 & 0.570 & -0.093 & 0.86 & -0.538 & -0.139 & 1.94 & 43.91 \\
\hline ICT7 & -0.095 & 0.330 & 10.90 & -0.031 & -0.028 & 0.08 & -0.757 & $-\underline{0.710}$ & 50.37 & $\underline{61.35}$ \\
\hline ICT8 & 0.271 & $\underline{0.815}$ & 66.42 & -0.183 & -0.299 & 8.91 & -0.826 & -0.296 & 8.75 & $\underline{84.09}$ \\
\hline$R_{c}{ }^{2}$ & & & 49.50 & & & 30.90 & & & 18.50 & \\
\hline P1 & -0.372 & $\underline{0.726}$ & 52.66 & 1.294 & $\underline{0.538}$ & 28.99 & 0.104 & -0.194 & 3.77 & $\underline{85.42}$ \\
\hline $\mathrm{P} 2$ & -0.115 & $\overline{0.170}$ & 2.88 & 0.350 & 0.539 & 29.08 & 0.161 & 0.078 & 0.61 & $\overline{32.57}$ \\
\hline P3 & 1.068 & 0.900 & 80.96 & -0.999 & 0.231 & 5.34 & -0.677 & -0.272 & 7.42 & 93.72 \\
\hline P4 & -0.016 & $\overline{0.222}$ & 4.92 & -0.551 & -0.514 & 26.41 & -0.273 & -0.197 & 3.88 & 35.22 \\
\hline P5 & 0.305 & 0.631 & 39.82 & 0.172 & $\overline{0.187}$ & 3.51 & 0.184 & -0.055 & 0.30 & 43.63 \\
\hline P6 & 0.294 & $\overline{0.475}$ & 22.52 & -0.180 & -0.170 & 2.87 & 0.950 & 0.820 & 67.28 & 92.68 \\
\hline
\end{tabular}

Note. Structure coefficients $\left(r_{s}\right)$ greater than $|0.45|$ are underlined. Communality coefficients $\left(h^{2}\right)$ greater than $45 \%$ are underlined. Coef $=$ standardized canonical function coefficient; $r_{s}=$ structure coefficient; $r_{s}{ }^{2}=$ squared structure coefficient; $h^{2}=$ communality coefficient.

Looking at Function 1 coefficients, the first two variables ICT1 (ICT use for biz-to-biz transactions), ICT2 (ICT use for biz-to-consumer transactions) and ICT8 (Quality of electricity supply) were primarily relevant $\left(r_{s}>0.7\right)$. This conclusion however was not supported by the squared structure coefficients considering only ICT1 and ICT8 had relatively high squared structure coefficients. Furthermore, these three variables (ICT1, ICT2 and ICT8) are all positive, indicating that they are all positively related. The last column of the table lists the communality coefficients which are simply the sum of the $r_{s}^{2}$. Sherry and Henson (2005) commented that the communalities can be viewed as an indication of how useful the variables were to the solution. We notice that primary relevant variables to the function were ICT1, ICT8 and then ICT2. This was supported by the squared structure coefficients which indicated the amount of variance the observed variable can contribute to the synthetic variable. 
The other side of the equation in Function 1 informs us that P3 (Effectiveness of marketing and branding to attract tourists) and P1 (Government prioritization of Travel and Tourism) were the primary contributors to the synthetic variable. Due to the fact that both variables of government effort are positive, they are positively related to all contributors from technology, all of them being positive as well.

Given that these results involve ICT use for biz-to-biz transactions (P1), quality of electricity supply (P8) and ICT use for biz-to-consumer transactions (P2) in the technology side of the function as well as Effectiveness of marketing and branding to attract tourist (P3) and Government prioritization of travel and tourism (P1) it makes sense to label this function as "Quality ICT towards Tourism branding".

Moving to Function 2, the coefficients in Table 3 suggest that the only technology variable of relevance is ICT2 (ICT use for biz-to-consumer transactions) although at very moderate level. As for government effort variables, P1 (Government prioritization of travel and tourism), P2 (Travel and tourism government expenditures) and P4 (Comprehensiveness of annual T\&T data) were the dominant variables, at moderate level as well. These variables were inversely related. Looking at the structure coefficients for the entire Function 2, ICT2 was negatively related to $\mathrm{P} 1$ and $\mathrm{P} 2$ while positively related to $\mathrm{P} 4$. Considering the dominant variables on both sides of the Function, it seems indicative of the focus on how the government makes tourism one of its priorities; therefore the function can be labeled "Tourism, a government priority".

In Function 3, there is only one dominant technology variable and only one dominant government effort variable that contributed to the function, namely ICT7 (Mobile Network Coverage) and P6 (Country brand strategy rating). A look at the structure coefficients for the entire function shows that ICT7 and P6 are negatively related. Mobile network services are mostly private; if the government runs interference, it might drive the quality of services down, which would negatively affect ratings on the country brand strategy. Therefore, we label this function "Technology away from Government".

\subsection{Redundancy Analysis}

As explained by Hair et al. (2010), the redundancy index was proposed as a measure of shared variance to overcome bias, misinterpretation and uncertainty that might exist with the use of squared canonical correlations, since they also provide an estimate of the shared variance between canonical variates. The redundancy index provides a summary measure of the ability of a set of variables to explain variation in the other set of variables. In the present case, the redundancy index helps identifying how much of technology's variance is given by the government effort and vice versa.

Table 4. Analysis Summary

\begin{tabular}{|c|c|c|c|c|}
\hline & \multicolumn{2}{|c|}{ Technology (\%) } & \multicolumn{2}{|c|}{ Government Effort (\%) } \\
\hline Variance Extracted & \multicolumn{2}{|c|}{85.08} & \multicolumn{2}{|c|}{100} \\
\hline Total Redundancy & \multicolumn{2}{|c|}{28.84} & \multicolumn{2}{|c|}{27.43} \\
\hline \multirow{2}{*}{ Canonical Function } & \multicolumn{2}{|c|}{ Variance Extracted (\%) } & \multicolumn{2}{|c|}{ Redundancy (\%) } \\
\hline & ICT & Gov. Eff. & ICT & Gov. Eff. \\
\hline 1 & 45.33 & 33.96 & 22,42 & 16.8 \\
\hline 2 & 8.85 & 16.03 & 2.73 & 4.95 \\
\hline 3 & 7.89 & 13.88 & 1.46 & 2.56 \\
\hline
\end{tabular}

Table 4 displays the total redundancy taking into account the six pairs identified, and the variance given by the other set is almost the same, though slightly higher in the case of technology which is given $28.84 \%$ variance by government efforts, whereas it gives $27.43 \%$ variance to the government efforts. Further results show the redundancy index of the first root, and it turns out that $22.42 \%$ variance of technology is given by the efforts of the government in tourism promotion whereas government effort is given $16.79 \%$ variance by the technology set of variables. In the case of function 2 and 3, the redundancy index is low and varies between 1 and $5 \%$.

The relationship between technology and government efforts in support of tourism is presented in the following figure where, based on the first canonical function, we identify the trend created by the association of the two constructs. However, the analysis conducted earlier is indicative that there is more than just a simple linear relationship between them. 


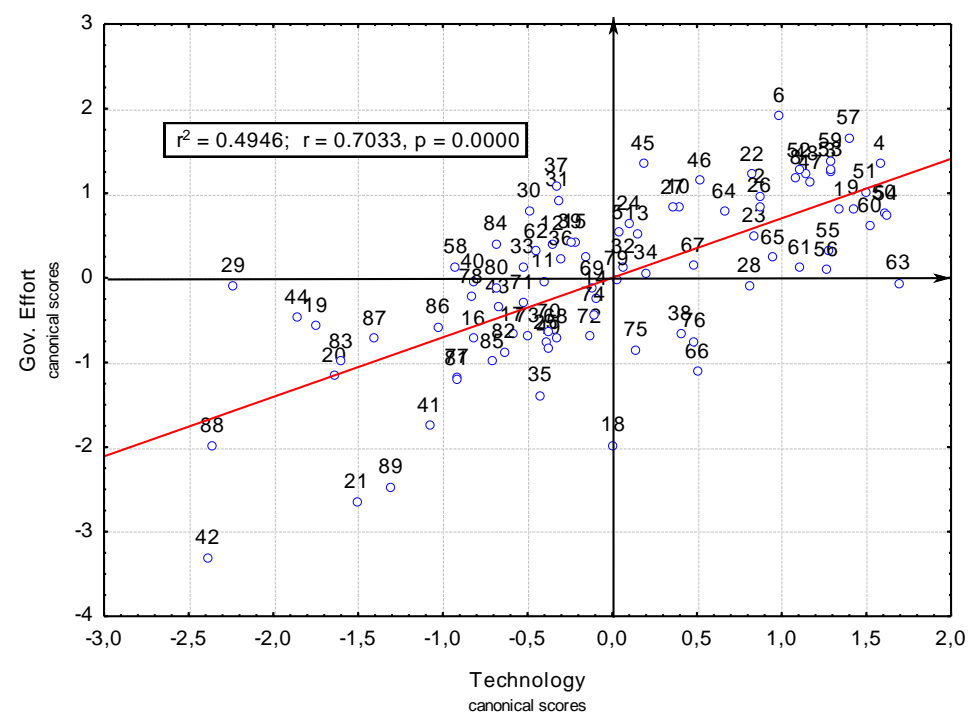

Figure 1. Canonical correlation of Technology and Government Effort

(see Appendix for countries number and name)

The previous figure, rather than focusing on countries positioning, illustrates the canonical correlation between technology and government efforts through the canonical scores of the first function for all 89 countries under analysis, considering the first function is the most important of all statistically significant functions extracted from the model. It clearly displays the existence of the relationship between both constructs.

\subsection{Cluster Analysis Results - TTCI comparison Among Groups}

For well-informed and oriented suggestions, a cluster analysis was conducted in order to group the countries in homogenous classes based on the two variables being studied, technology and government effort in support to the tourism industry. The countries were classified in five groups via k-means clustering method based on the two factors being discussed considering that is the most appropriate number of groups that fits the study objectives.

Table 5. An Analysis of Tourism Competitiveness

\begin{tabular}{lccccc}
\hline Cluster (Members) & $\mathrm{I}(\mathrm{n}=20)$ & $\mathrm{II}(\mathrm{n}=28)$ & $\mathrm{III}(\mathrm{n}=9)$ & $\mathrm{IV}(\mathrm{n}=10)$ & $\mathrm{V}(\mathrm{n}=22)$ \\
\hline Coordinates of Cluster center & & & & & \\
Technology (x) & 3.82 & 4.99 & 5.21 & 3.65 & 6.09 \\
Gov. Efforts (y) & 4.86 & 4.38 & 5.67 & 3.62 & 5.17 \\
\hline TTCI & 3.65 & 4.09 & 4.27 & 3.30 & 4.79 \\
\hline \multicolumn{1}{c}{ Characteristics of } & $2.60 \leq \mathrm{x} \leq 4.50$ & $4.20 \leq \mathrm{x} \leq 5.70$ & $4.80 \leq \mathrm{x} \leq 5.50$ & $2.50<\leq \mathrm{x} \leq 4.30$ & $5.60 \leq \mathrm{x} \leq 6.50$ \\
$\quad$ Clusters & $3.30 \leq \mathrm{y} \leq 5.80$ & $3.60 \leq \mathrm{y} \leq 5.00$ & $5.20 \leq \mathrm{y} \leq 6.20$ & $3.20 \leq \mathrm{y} \leq 4.00$ & $4.40 \leq \mathrm{y} \leq 6.00$ \\
\hline
\end{tabular}

As previously shown in Table 5, the countries have been clustered into five groups, based on two conditions met at the same time. For example, in the first group, the technology level of the countries varies between 2.60 and 4.50 while their government's effort in tourism varies between 3.30 and 5.80. For this group, their average tourism competitiveness is 3.65. Further evidence of the grouping is presented in the next figure that shows the plot of means for each cluster. 


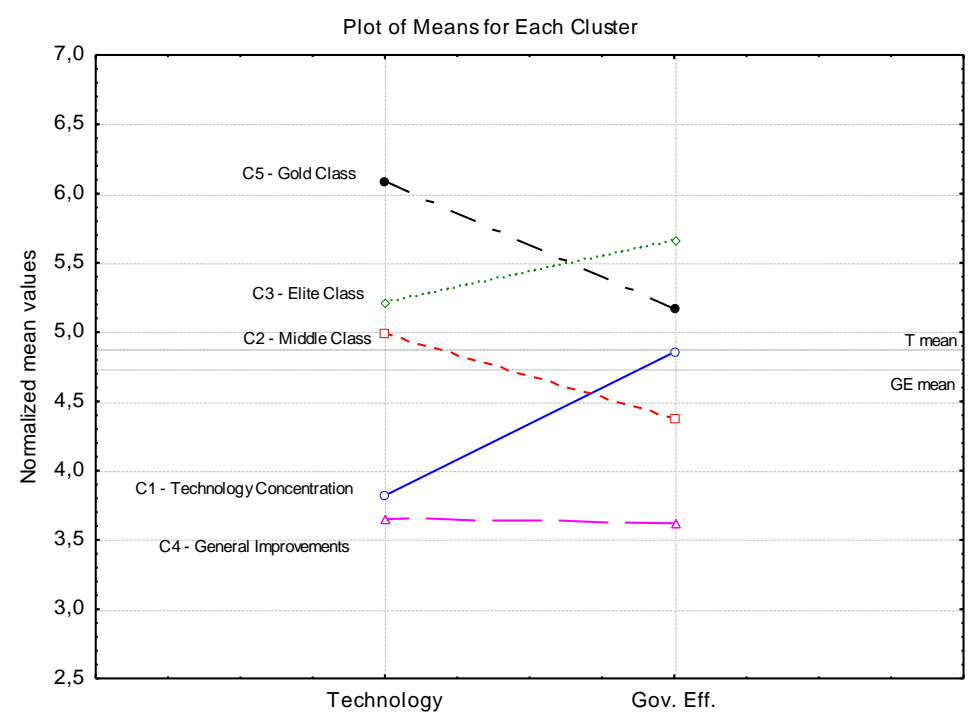

Figure 2. Means of each group constituted (see Appendix for members of each cluster)

In figure 2, each group is given a name based on the mean of each variable. Note that each country can identify the cluster it belongs to by visiting the Appendix. Two top performers were identified, cluster 3 named "Elite class" and cluster 5 named "Gold class". The Gold class is a technology oriented group considering that it outperformed any other cluster when it comes to technology; the technology index of the countries vary between 5.60 and 6.50 while they are not the top performers in government efforts. This group included European and Asia-Pacific country, with only two countries from the Americas: United States and Canada. Government effort within this group ranged between 4.40 and 6.00 with an average tourism competitiveness of 4.79 . The surprise absent from this group is Spain, best performer in terms of tourism competitiveness; due to its technology level not falling within the range, it has therefore been counted out. The Elite class, second best performer, is also considered a top class because its technology level and its government effort are good. In fact, the government effort is better than the Gold class and varies between 5.20 and 6.20 whereas the technology indicator varies between 4.80 and 5.50. With an average tourism competitiveness of 4.27, Spain falls into this category. Besides the top performers, there is the "Middle Class" displaying an above average technology level ranging between 4.20 and 5.70, a government effort between 3.60 and 5.00 and an average tourism competitiveness (4.09) which corresponds to the average competitiveness of the sample. While the first two groups represent the situation desired by all countries, there are two remaining groups which show weakness in either or both of the constructs under study. The "Technology Concentration" class is one in which clear improvements in technology level are needed although the government effort is average. This group has an average tourism competitiveness of 3.65, a technology indicator below average (between 2.60 and 4.50) coupled with efforts from the government to promote tourism being above average (between 3.30 and 5.80). The last group indicates improvements are needed in either construct, both being lower than average, which explains the label "General Improvements" of this group. As a result, the average competitiveness of tourism (3.30) is low compared to the other groups.

Nothing reaches perfection in a competitive world. As countries compete almost about everything and anything, there is always a need for improvements in order to benchmark or compete. It would be easier to consider the top performers as groups where no improvements are needed. However, countries in these groups can still improve both factors towards their peak if possible. The difference between the two groups is that the Gold class will be better off focusing on government efforts while the Elite class should devote more efforts in technology's betterment. The Middle class needs to improve both factors to reach either of the top-performers but a greater focus should be on government efforts. Technology concentration is where technology improvements are mandatory at least to reach an average level; government efforts can be worked on aiming at peak level rather than average. General improvements, the bottom class where both variables are way below average, indicates that both factors need a dedication to their improvements. The previous analysis proved that actions aiming at improving technology and government efforts should be simultaneous because they mutually influence each other's variation. Some actions for improvements could be either implementing policies that attract more foreign direct investment in the industry, or policies that promote a better quality of electricity supply, or even policies that heavily promote tourism, augmentation of government expenditures in tourism, policies for better service quality, security, etc. 


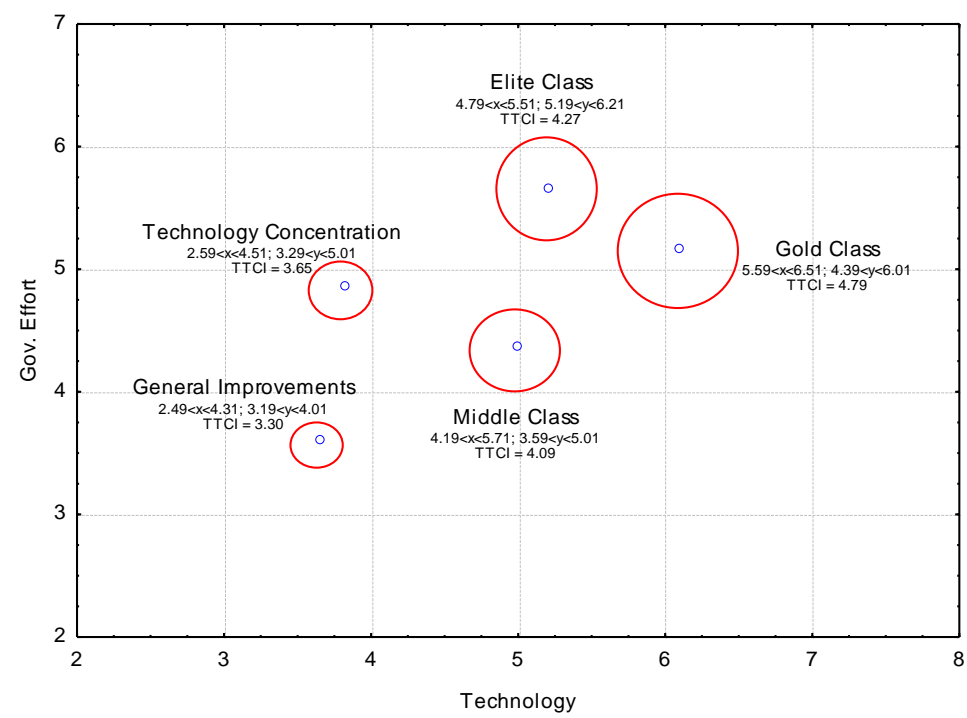

Figure 3. Cluster centers and distribution of tourism competitiveness

Figure 3 introduces a scatter which represents the centers of each groups as well as their characteristics, including their respective average tourism competitiveness achievement. It should not be ignored however that within one group, there are significant differences between members constituting the group. The bubbles are designed just to show the competitiveness achievements between clusters, therefore the better the Tourism Competitiveness performance, the bigger the bubble.

The communalities presented earlier in Table 3 indicated that, on the technology variable set, there were three major contributors to the canonical solution in the following order: ICT1, ICT2 and ICT8. A secondary contribution was displayed by ICT 7 (Mobile Network Coverage). The other set also had three major contributors : P3, P6 and P8. While it is clear that travel and tourism relies on more pillars than just technology and government effort, it is important to understand that these two have displayed the highest weight (Gooroochurn \& Sugiyarto, 2005) and are of great importance to the index, whether taken separately or together. In the present study, the existence of a complex and multifaceted relationship between the two construct has been demonstrated and improving tourism competitiveness could start by the improvement of these two, taken together rather than on their own, that is precisely the reason they are considered a two-headed animal within the index. An animal possessing two heads does not mean it can travel two different paths at the same time; rather, the two heads would need to harmoniously cooperate and lead the body in one single direction, which is technology and government effort's case. Further considerations prove that individual indicators constituting the sets of variables should be highly regarded while aiming at improvements of tourism competitiveness, such as ICT use for biz-to-biz transactions, ICT use for biz-to-consumer transactions, quality of electricity supply, government prioritization of travel and tourism industry, effectiveness of marketing and branding as well as country brand strategy rating. For example, the relationship of technology and government effort could be illustrated as follow: without a stable quality of electricity supply, attracting the today's tourist becomes harder considering the traveler needs stable electricity in order to fully access all advantages of technologies, stay connected with family and friends or even for leisure and recreation purposes.

This study unveils the complex relationship between technology (ICT Readiness) and government effort in tourism (Prioritization of Travel and Tourism). More than just a simple linear relationship, the existence of three significant layers was discovered, the first layer being the most important. Canonical correlation proved therefore to be the appropriate technique to investigate their relationship since it allowed to mirror the depth and complexity of said relationship. Moreover, canonical correlation analysis limited the probability of finding a relationship when it really does not exist because it allowed for simultaneous comparisons among the variables rather than requiring many statistical tests be conducted (Sherry \& Henson, 2005).

Countries from three different regions are included in the analysis, namely Europe, Asia-Pacific and the Americas. The focus not being primarily on regions, the countries aiming at improving their travel and tourism competitiveness should not prioritize technology or government effort but should rather accommodate the simultaneous development of both. These constructs share their variance in a way that is approximately the same, 
which is indicative of both constructs having almost a similar impact on each other within the competitiveness index. Therefore, the ideal situation would be to work at improving both at the same time considering failure to do so could easily have negative drawbacks on how well any of them would perform taken separately, which would later influence the overall tourism competitiveness, as it is arguably the case within the Technology Concentration group for example. Working on both at the same time does not however imply they will require the same focus. With the known importance of technology to tourism, and the proven mutual importance of both constructs to each other, private investors may decide to invest in the sector while being assured of the government efforts to value their investments without interfering in private matters. If tourism competitiveness was solely depending on these two constructs, the various stakeholders within society would therefore make informed decisions for the betterment of their economy and they would know precisely where to concentrate their efforts in order to reach new levels of development via a competitive tourism industry.

This study contributes to the body of literature in that it unveils the relationship of two important constructs related to tourism competitiveness. Harmonious cooperation between technology and government effort in support to the tourism industry only lean towards the betterment of overall tourism competitiveness as approached and defined by the World Economic Forum.

\section{Conclusion}

The findings of this research support the existence of a multi-dimensional and complex relationship between technology and government effort towards tourism competitiveness, respectively referred to as Information and Communication Technology Readiness and Prioritization of Travel and Tourism within the TTCI. Canonical Correlation proved to be a useful technique allowing the investigation of the multivariate shared relationship between constructs, leaning on the flexibility of the method (Fox \& Hammond, 2017; Sherry \& Henson, 2005). Transposed at the country level, these findings indicate that countries seeking improvements of their tourism competitiveness index, rather than emphasizing on either of these two, should work at improving both, given the way they influence the variation of each other and they can find which cluster they belong to in the Appendix in order to use the recommendations that best fit their situation. This conclusion is supported by the redundancy analysis which reveals the shared variance between the constructs. Moreover, it is important to understand that the development of technology in a touristic context can be beneficial, as it can be a tool to reinforce tourism activities, build a solid brand and promote tourism activities at a wider scale. It would be a win-win situation as a well-organized government can only favor technology development if no interference is running.

The analyses show that technology can be a tool that best serves the government effort in support of the tourism industry. At the same time, one of the functions extracted is pointing at the break up point between technology and the government activities. It is true that redundancy analysis shows both constructs influencing each other; however, they do so in a limited manner, which indicates rather than being a total blend, they only influence each other to a certain level and there is separation in the roles they both have to play. Countries should try at best to emphasize on balanced cooperation between technology and government efforts, making sure there is no excessive interaction. This is further evidence of the two-headed animal nature these constructs display within the index: two heads won't necessarily allow an animal to go in two opposite directions, the heads have to cooperate and lead the body in one direction; they have to be worked on at the same time to improve the industry's competitiveness.

The present study is based on data presented by the World Economic Forum within the TTCR 2017: Paving the way for a more sustainable and inclusive future. The findings can't be generalized and are specific to the competitiveness of the countries in 2017. However, repeatability of similar studies for other years will contribute to increase knowledge on the topic. Considering three regions were taken into consideration within the dataset, extending the results to the whole set would be meaningless without prior analyses.

Mention is made in the literature of how important technology is to tourism competitiveness and there is no doubt its importance might keep growing due to the fast development of new technologies. Tourists of our era rely on technology for information gathering, travel planning and convenience while tourists from the past had limited access to information (Chung \& Koo, 2015). Therefore, further studies might be oriented towards the benefits applying big data analytics could bring to tourism competitiveness, considering that big data is now the trend and applications of big data are found in almost every aspects of service provision in tourism industry.

\section{References}

Aramendia-Muneta, M. E., \& Ollo-Lopez, A. (2013). ICT Impact on tourism industry. International Journal of Management Cases, 15(2), 87-98. 
Aronsson, L. (2000). The development of sustainable tourism. London: Continuum.

Augustin, J. L. P., \& Liaw, S. Y. (2017). Tourism competitiveness index of the Asia-Pacific region through consistency analysis. Asia Pacific Journal of Tourism Research, 12, 1295-1307. https://doi.org/10.1080/10941665.2017.1391855

Bojnec, S., \& Kribel, Z. (2004). Information and Communication Technology in Tourism, in Intellectual Capital and Knowledge Management. Proceedings of the 5th International Conference of the Faculty of Management Koper, University of Primorska, (pp. 445-454). Portoroz, Slovenia. Consulté le November 18-20, 2004, sur http://www2.fm-kp.si/zalozba/ISB/961-6486-71-3/445-454.pdf

Bouquet, M., \& Winter, M. (1987). Introduction: Tourism Politics and Practice. Dans e. M. Bouquet and M. Winter, Who from their Labours Rest: Conflict and Practice in Rural Tourism (pp. 1-8). Aldershot: Gower.

Bramwell, B. (2011). Governance, the state and sustainable tourism: a policital economy approach. Journal of Sustainable Tourism, 19(4-5), 459-477. https://doi.org/10.1080/09669582.2011.576765

Buhalis, D. (2000). Marketing the competitive destination in the future. Tourism Management, 21(1), 97-116. https://doi.org/10.1016/S0261-5177(99)00095-3

Buhalis, D., \& Kaldis, K. (2008). eEnabled internet distribution for small and medium sized hotels: the case of Athens. Tourism Recreation Research, 33(1), 67-81. https://doi.org/10.1080/02508281.2008.11081291

Buhalis, D., \& Law, R. (2008). Progress in information technology and tourism management: 20 years on and 10 years after the Internet the state of e-tourism research. Tourism Management, 29, 609-623. https://doi.org/10.1016/j.tourman.2008.01.005

Buhalis, D., \& O'Connor, P. (2005). Information communication technology revolutionizing tourism. Tourism Recreation Research, 30(3), 7-16. https://doi.org/10.1080/02508281.2005.11081482

Chan, N. I., \& Guillet, B. D. (2011). Investigation of Social media marketing: how does the hotel industry in Hong Kong performs in marketing on social media websites? Journal of Travel Tourism Market, 28, 345-368. https://doi.org/10.1080/10548408.2011.571571

Chung, N., \& Koo, C. (2015). The use of social media in travel information search. Telematics and Informatics, 32(2015), 215-229. https://doi.org/10.1016/j.tele.2014.08.005

Citrin, J. (1974). Comment: the political relevance of trust in government. The American Political Science Review, 68(3), 973-988. https://doi.org/10.2307/1959141

Crotti, R., \& Misrahi, T. (2015). The Travel and Tourism Competitiveness 2015: Growth through shocks. Récupéré sur http://www.weforum.org

Crotti, R., \& Misrahi, T. (2017). The Travel and Tourism Competitiveness Report 2017: Paving the way for a more sustainable and inclusive future. Récupéré sur http://www.weforum.org

Crouch, G., \& Richie, J. R. (1999). Competitive tourism destinations: combining theories of comparative advantage. Working Paper. Ninth Australian tourism and hospitality research conference. Adelaide.

Crouch, G., \& Ritchie, J. R. (1999). Tourism, Competitiveness, and Societal Prosperity. Journal of Business Research, 44(3), 137-152. https://doi.org/10.1016/S0148-2963(97)00196-3

Dos Santos, B. L., Peffers, G. K., \& Mauer, D. C. (1993). The impact of information technology investment announcements on the market value of the firm. Information Systems Research, 4(1), 1-23. https://doi.org/10.1287/isre.4.1.1

Dredge, D., \& Jenkins, J. (2007). Tourism and policy and planning. Milton: John Wiley.

Dupeyras, A., \& MacCallum, N. (2013). Indicators for measuring Competitiveness in Tourism: A guidance document. OECD Publishing. Consulté le 02 2013, sur.

Dwyer, L., \& Kim, C. (2003). Destination competitiveness: determinants and indicators. Current issues in tourism, 6(5), 369-414. https://doi.org/10.1080/13683500308667962

Dwyer, L., Forsyth, P., \& Rao, P. (2000b). The price competitiveness of travel and tourism: A comparison of 19 destinations. Tourism Management, 21, 9-22. https://doi.org/10.1016/S0261-5177(99)00081-3

Dwyer, L., Mistilis, N., Forsyth, P., \& Rao, P. (2000a). Sectoral analysis of price competitiveness of tourism: An international comparison. International Journal of Tourism Research, 3, 123-139. https://doi.org/10.1002/jtr.292

Edwards, J. R., \& Bagozzi, R. P. (2000). On the Nature and Direction of Relationships Between Constructs and Measures. Psychological Methods, 5(2), 155-174. https://doi.org/10.1037/1082-989X.5.2.155

Elliott, J. (1997). Tourism: Politics and public sector management. London: Routledge. 
Enright, M. J., \& Newton, J. (2004). Tourism Destination Competitiveness: a quantitative approach. Tourism Management, 25(6), 777-788. https://doi.org/10.1016/j.tourman.2004.06.008

Enright, M. J., \& Newton, J. (2005). Determinants of Tourism Destination Competitiveness in Asia-Pacific: Comprehensiveness and Universality. Journal of Travel Research, 43(4), 339-350. https://doi.org/10.1177/0047287505274647

Fox, S., \& Hammond, S. (2017). Investigating the multivariate relationship betwenn impulsivity and psychopathy using canonical correlation analysis. Personality and Individual Differences, 111(2017), 187-192. https://doi.org/10.1016/j.paid.2017.02.025

Garau, J. (2006). Proposal of two complementary indexes for measuring tourism competitiveness of Mediterranean destinations: outgoing results of a pilot study from the industry side'. International Conference of Trends, Impacts and Policies on Tourism Development, (pp. 18-20). Palma de Mallorca.

Gomezelj, D. O., \& Mihalic, T. (2008). Destination competitiveness: applying different models, the case of Slovenia. Tourism Management, 29(2), 294-307. https://doi.org/10.1016/j.tourman.2007.03.009

Gooroochurn, N., \& Sugiyarto, G. (2005). Competitiveness indicators in the travel and tourism industry. Tourism Economics, 11(1), 25-43. https://doi.org/10.5367/0000000053297130

Haahti, A. J., \& Yavas, U. (1983). Tourists perceptions of Finland and selectd European countries as travel destinations. European Journal of Marketing, 17(2). https://doi.org/10.1108/EUM0000000004833

Hair, J. F., Black, W. C., Babin, B. J., \& Anderson, R. E. (2010). Multivariate Data Analysis: A Global Perspective (éd. Seventh Edition). New Jersey: Pearson.

Khin, E. E., Daengbuppha, J., \& Nonsiri, P. (2014). Destination Competitiveness: A structural model for measuring attributes competitiveness of Bagan, Myanmar. International Journal of Business, Economics and Law, 4(2), 51-59.

Kozak, M., \& Rimmington, M. (1998). Benchmarking: destination attractiveness and small hospitality business performance. International Journal of Contemporary Hospitality Management, 10, 74-78. https://doi.org/10.1108/09596119810227767

Kozak, M., \& Rimmington, M. (1999). Measuring tourist destination competitiveness: Conceptual considerations and empirical findings. International Journal of Hospitality Management, 18(3), 184-188. https://doi.org/10.1016/S0278-4319(99)00034-1

Lee, C. K., Var, T., \& Blaine, T. W. (1996). Determinants of inbound tourism expenditure. Annals of Tourism Research, 23(3), 527-542. https://doi.org/10.1016/0160-7383(95)00073-9

Leontitis, A., \& Pagge, J. (2007). A simulation approach on Cronbach's alpha statistical significance. Mathematics and Computers in Simulation, 73(5), 336-340. https://doi.org/10.1016/j.matcom.2006.08.001

Madrigal, R. (1995). Residents' Perceptions and the Role of Government. Annals of Tourism Research, 22(1), 86-102. https://doi.org/10.1016/0160-7383(94)00070-9

Mihalic, T. (2007). ITC and productivity - the case of the Slovenian travel industry. Productivity in Tourism: fundamentals and concepts for achieving growth and competitiveness, pp. 167-188.

Nunkoo, R. (2015). Tourism development and trust in local government. Tourism Management, 46, 623-634. https://doi.org/10.1016/j.tourman.2014.08.016

Papatheodorou, A. (2002). Exploring competitiveness in Mediterranean resorts. Tourism Economics, 8(2), 133-150. https://doi.org/10.5367/000000002101298034

Pearce, P. L. (1989). Tourist Development (2nd ed.). London: Longman.

Perles, J. F. (2004). Turismo, Ventaja competitiva y Desarollo Local, Doctoral Thesis. Universidad de Alicante.

Pulido-Fernandez, J. I., \& Rodriguez-Diaz, B. (2016). Reinterpreting the World Economic Forum's global tourism competitiveness index. Tourism Management Perspectives, 20, 131-140. https://doi.org/10.1016/j.tmp.2016.08.001

Ritchie, B. J., \& Crouch, G. I. (2003). The competitive destination, a sustainable tourism perspective. Cambridge: Cabi Publishing. https://doi.org/10.1079/9780851996646.0000

Ruhanen, L. (2013). Local Development: facilitator or inhibitor of sustainable tourism development. Journal of Sustainable Tourism, 21(1), 80-98. https://doi.org/10.1080/09669582.2012.680463

Scott, B. R., \& Lodge, G. C. (1985). US Competitiveness in the World Economy. Boston, MA: Havard Business School Press. 
Sherry, A., \& Henson, R. K. (2005). Conducting and Interpreting canonical correlation analysis in personality research: A user-friendly primer. Statistical Development and Applications, 84(1), 37-48. https://doi.org/10.1207/s15327752jpa8401_09

Sigala, M., Christou, E., \& Gretzel, U. (2012). Social media in travel, tourism and hospitality: Theory, Practice, and cases. Great Britain: MPG Books Group, UK.

Tabachnick, B. G., \& Fidell, L. S. (1996). Using multiariate statistics (éd. 3rd ed.). New York: Harper-Collins.

Tanja, A., Markovic, V., Davidovic, N., \& Jovanovic, T. (2011). Integrated Model of Destination Competitiveness. Geographica Pannonica, 15(2), 58-69. https://doi.org/10.5937/GeoPan1102058A

Tavakol, M., \& Dennick, R. (2011). Making sense of Cronbach's alpha. International Journal of Medical Education, 2, 53-55. https://doi.org/10.5116/ijme.4dfb.8dfd

Wang, D., \& Ap, J. (2013). Factors affecting tourism policy implementation: A conceptual framework and a case study in China. Tourism Management, 36, 221-233. https://doi.org/10.1016/j.tourman.2012.11.021

Wang, Y., \& Bramwell, B. (2012). Heritage protection and tourism development priorities in Hangzhou, China: a political economy and governance perspective. Tourism Management, 33(4), 988-998. https://doi.org/10.1016/j.tourman.2011.10.010

Xiang, Z., \& Gretzel, U. (2010). Role of social media in online travel information search. Tourism Management, 31(2), 179-188. https://doi.org/10.1016/j.tourman.2009.02.016

\section{Appendix}

Note: Statistical Significance test for the Model

Effect: within cells regression / Multivariate Tests of Significance ( $\mathrm{S}=6, \mathrm{M}=1 / 2, \mathrm{~N}=36$ 1/2)

\begin{tabular}{lcccrc}
\hline Test name & Value & Approx. $F$ & Hypothesis $D F$ & Error $D F$ & Significance of $F$ \\
\hline Pillais's & 1.232 & 2.584 & 48.00 & 480.00 & .000 \\
Hotelling's & 1.929 & 2.947 & 48.00 & 440.00 & .000 \\
Wilks's & 0.220 & 2.804 & 48.00 & 379.09 & .000 \\
Roy's & 0.495 & & & &
\end{tabular}

Note: Dimension Reduction Analysis

\begin{tabular}{lccccc}
\hline Roots & Wilks $\lambda$ & $F$ & Hypothesis $D F$ & Error $D F$ & Significance of $F$ \\
\hline 1 to 6 & 0.220 & 2.804 & 48.00 & 373.09 & .000 \\
2 to 6 & 0.435 & 2.016 & 35.00 & 322.13 & .001 \\
3 to 6 & 0.629 & 1.598 & 24.00 & 269.83 & .041 \\
4 to 6 & 0.772 & 1.417 & 15.00 & 215.73 & .141 \\
5 to 6 & 0.903 & 1.033 & 8.00 & 158.00 & .414 \\
6 to 6 & 0.988 & 0.334 & 3.00 & 80.00 & .800 \\
\hline
\end{tabular}

Note: Standardized Canonical Coefficients for ICT Readiness

\begin{tabular}{lccc}
\hline \multirow{2}{*}{ Variable } & \multicolumn{3}{c}{ Function No. } \\
\cline { 2 - 4 } & 1 & 2 & 0.804 \\
ICT1 & 1.330 & 1.591 & -0.115 \\
ICT2 & -0.459 & -1.896 & -0.309 \\
ICT3 & 0.010 & -0.874 & 1.091 \\
ICT4 & -0.178 & 0.353 & 0.167 \\
ICT5 & 0.011 & 0.086 & -0.538 \\
ICT6 & -0.020 & 0.570 & -0.757 \\
ICT7 & -0.095 & -0.031 & -0.826 \\
ICT8 & 0.271 & -0.183 & \\
\hline
\end{tabular}

Note: Correlations between ICT Readiness and canonical variables

\begin{tabular}{lccc}
\hline \multirow{2}{*}{ Variable } & \multicolumn{3}{c}{} \\
\cline { 2 - 4 } & 1 & Function & 0.048 \\
ICT1 & 0.965 & -0.170 & 0.085 \\
ICT2 & 0.764 & -0.542 & -0.063 \\
ICT3 & 0.631 & -0.414 & 0.084 \\
ICT4 & 0.666 & -0.327 & 0.019 \\
ICT5 & 0.292 & -0.089 & -0.139 \\
ICT6 & 0.641 & -0.093 & -0.710 \\
ICT7 & 0.330 & -0.028 & -0.296 \\
ICT8 & 0.815 & -0.299 & \\
\hline
\end{tabular}


Note: Standardized canonical coefficients for Prioritization of Travel and Tourism

\begin{tabular}{lccc}
\hline Variables & 1 & 2 & 3 \\
\hline P1 & -0.372 & 1.294 & 0.104 \\
P2 & -0.115 & 0.350 & 0.161 \\
P3 & 1.068 & -0.999 & -0.677 \\
P4 & -0.016 & -0.551 & -0.272 \\
P5 & 0.305 & 0.172 & 0.184 \\
P6 & 0.294 & -0.180 & 0.950 \\
\hline Note: Correlations between Prioritization of Travel and Tourism and canonical variables & 3 \\
\hline Variables & 1 & 2 & -0.194 \\
P1 & 0.726 & 0.538 & 0.078 \\
P2 & 0.170 & 0.539 & -0.272 \\
P3 & 0.900 & 0.231 & -0.197 \\
P4 & 0.222 & -0.514 & -0.055 \\
P5 & 0.631 & 0.187 & 0.820 \\
P6 & 0.475 & -0.170 & \\
\hline
\end{tabular}

\section{First Canonical Function}

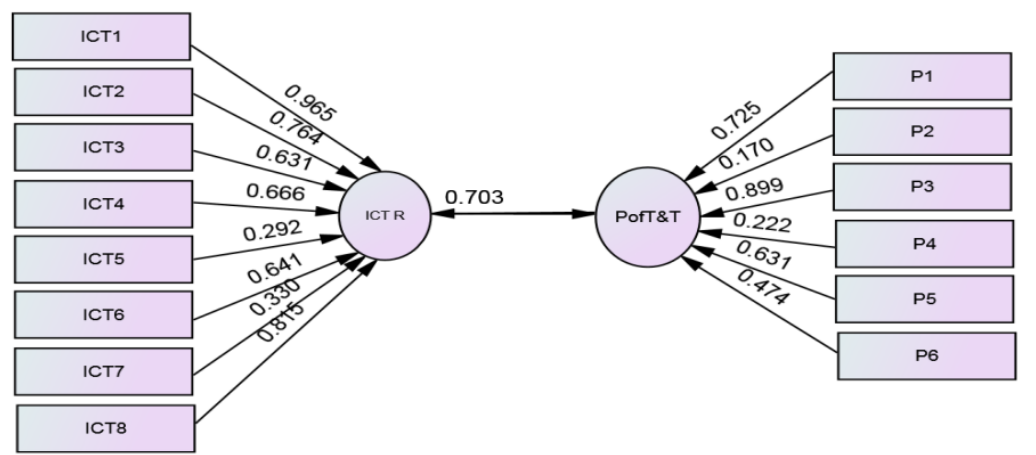

Second Canonical Function

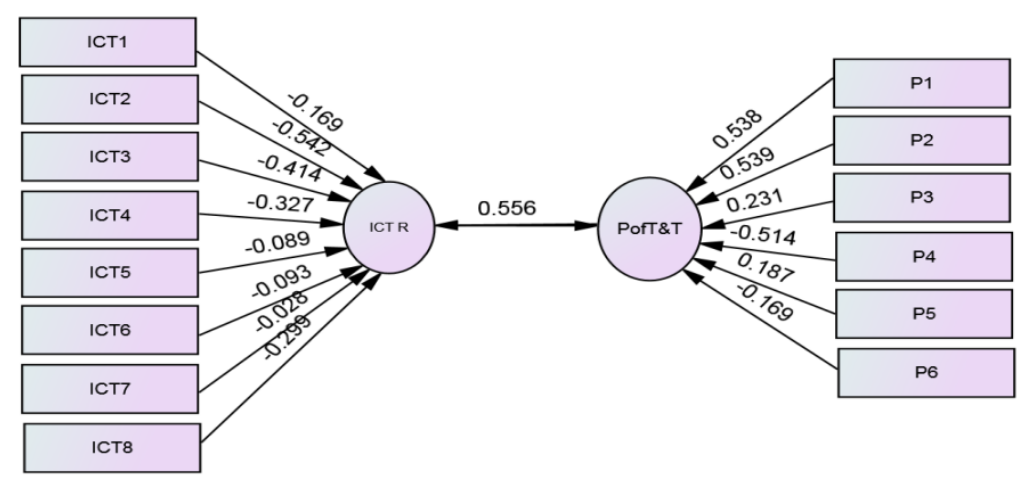

Third Canonical Function

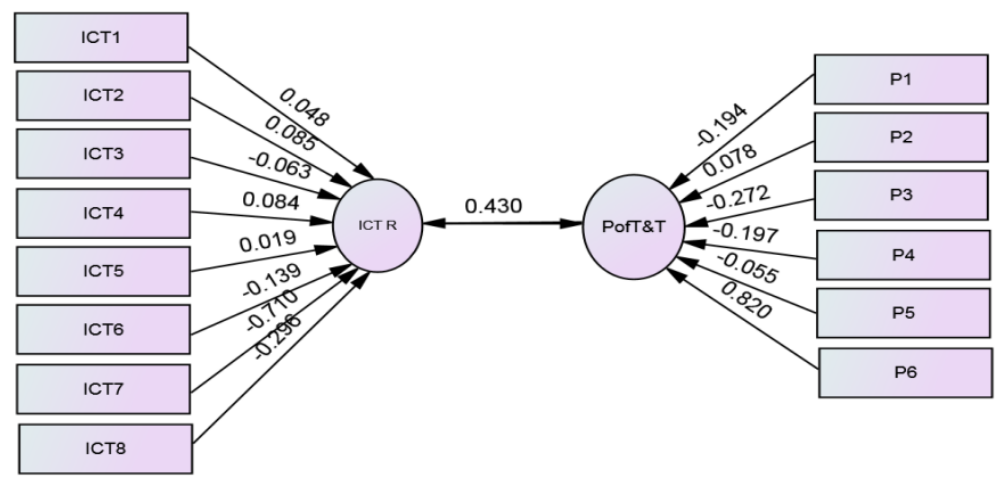

Note: Canonical Loadings and Correlations for the three canonical functions extracted 
List of the countries taken in the respective order of analysis:
1- Japan 2- Australia
3- Hong Kong 4- Singapore
5- China 6- New Zealand
7- Korea (Rep) 8- Malaysia
9- Taiwan 10- Thailand 11- India 12- Indonesia
13- Sri Lanka 14- Vietnam
15- Philippines 16- Lao PDR 17- Cambodia 18- Mongolia
19- Nepal 20- Pakistan 21- Bangladesh

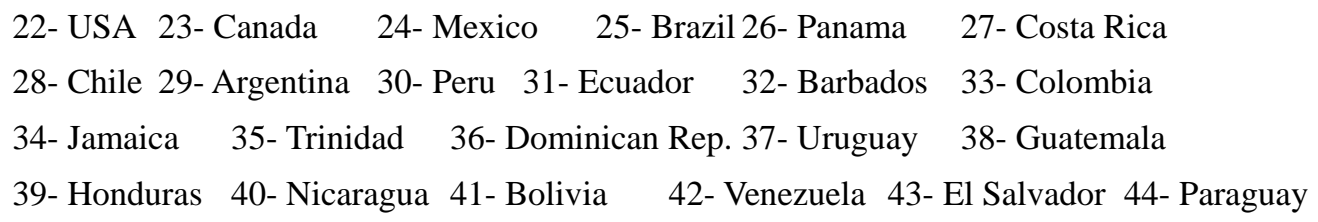

45- Spain 46- France 47- Germany 48- U.K 49- Italy 50- Switzerland

51- Austria 52- Portugal 53- Netherlands 54- Norway 55-Sweden 56- Belgium

57- Ireland 58- Greece 59- Iceland 60- Luxembourg 61- Denmark 62- Croatia

63- Finland 64- Malta 65- Estonia 66-Czech Rep.67- Slovenia 68- Russian F.

69- Turkey 70- Bulgaria 71- Poland 72- Hungary 73-Cyprus 74- Latvia

75- Lithuania 76- Slovak Rep 77- Romania 78-Georgia 79- Azerbaijan 80- Montenegro

81- Kazakhstan82- Armenia 83- Ukraine 84- Macedonia 85- Serbia86- Albania

87- Bosnia and Herzegovina 88- Kyrgyz Republic 89- Moldova

\begin{tabular}{|c|c|}
\hline \multicolumn{2}{|r|}{ Members of each Cluster } \\
\hline $\begin{array}{l}\text { Cluster } 1 \text { Technology } \\
\text { Concentration }\end{array}$ & $\begin{array}{l}\text { Indonesia, Sri-Lanka, Philippines, Lao PDR, Cambodia, Nepal, Mexico, Panama, Peru, Ecuador, } \\
\text { Dominican Rep., Guatemala, Honduras, Nicaragua, El Salvador, Paraguay, Georgia, Armenia, } \\
\text { Ukraine, Albania ( } 20 \text { Countries: } 6 \text { Asia-Pacific, } 10 \text { Americas, } 4 \text { Europe) }\end{array}$ \\
\hline $\begin{array}{l}\text { Cluster2 } \\
\text { Middle Class }\end{array}$ & $\begin{array}{l}\text { China, Malaysia, Taiwan, Thailand, Brazil, Chile, Argentina, Colombia, Trinidad \& T., Italy, } \\
\text { Belgium, Croatia, Czech Republic, Slovenia, Russian Federation, Turkey, Bulgaria, Poland, } \\
\text { Hungary, Latvia, Lithuania, Slovak Republic, Romania, Azerbaijan, Montenegro, Kazakhstan, } \\
\text { Macedonia FY, Serbia (28 Countries: } 4 \text { Asia-Pacific, } 5 \text { Americas, } 19 \text { Europe) }\end{array}$ \\
\hline $\begin{array}{c}\text { Cluster } 3 \\
\text { Elite Class }\end{array}$ & $\begin{array}{l}\text { Costa Rica, Barbados, Jamaica, Uruguay, Spain, Portugal, Greece, Malta, Cyprus (9 Countries: } 4 \\
\text { Americas, } 5 \text { Europe) }\end{array}$ \\
\hline $\begin{array}{c}\text { Cluster } 4 \\
\text { General Improvements }\end{array}$ & $\begin{array}{l}\text { India, Vietnam, Mongolia, Pakistan, Bangladesh, Bolivia, Venezuela, Bosnia and Herzegovina, } \\
\text { Kyrgyz Republic, Moldova (10 Countries: } 5 \text { Asia-Pacific, } 2 \text { Americas, } 3 \text { Europe) }\end{array}$ \\
\hline $\begin{array}{l}\text { Cluster } 5 \\
\text { Gold Class }\end{array}$ & $\begin{array}{l}\text { Japan, Australia, Hong Kong SAR, Singapore, New Zealand, Korea Rep., United States, Canada, } \\
\text { France, Germany, United Kingdom, Switzerland, Austria, Netherlands, Norway, Sweden, } \\
\text { Ireland, Iceland, Luxembourg, Denmark, Finland, Estonia (22 Countries: } 6 \text { Asia-Pacific, } 2 \\
\text { Americas, } 14 \text { Europe) }\end{array}$ \\
\hline
\end{tabular}

\section{Copyrights}

Copyright for this article is retained by the author(s), with first publication rights granted to the journal.

This is an open-access article distributed under the terms and conditions of the Creative Commons Attribution license (http://creativecommons.org/licenses/by/4.0/). 